\title{
A COMPATIBILIDADE DOS METADADOS DISPONÍVEIS EM SISTEMAS VGI COM O PERFIL DE METADADOS EMPREGADO NA INFRAESTRUTURA NACIONAL DE DADOS ESPACIAIS DO BRASIL (INDE-BR)
}

\section{The compatibility of metadata available at VGI systems with the metadata profile employed at the Brazilian National Spatial Data Infrastructure (INDE-BR)}

\author{
João Vitor Meza Bravo ${ }^{1}$ \\ Silvana Philippi Camboim ${ }^{1}$ \\ André Luiz Alencar De Mendonça² \\ Claudia Robbi Sluter ${ }^{1}$
}

\begin{abstract}
${ }^{1}$ Universidade Federal do Paraná, Setor de Ciências da Terra - Departamento de Geomática, Programa de Pós-Graduação em Ciências Geodésicas, Caixa Postal 19001, 8131 - 990, Curitiba, Paraná, Brasil. Contato: jvmbravo@gmail.com; silvanacamboim@gmail.com; robbisluter@gmail.com
\end{abstract}

2Universidade do Estado do Amazonas, Escola superior de tecnologia - Curso de Tecnologia em agrimensura, Av. Darcy Vargas 1200, CEP 69050-020, Manaus, Amazonas, Brasil. Contato: andremals@hotmail.com

\section{Resumo:}

As informações geográficas voluntárias têm sido investigadas por pesquisadores e agências oficiais de mapeamento, os quais tentam compreender como indivíduos sem conhecimento formalizado em cartografia podem contribuir para a construção das bases cartográficas oficiais. Em países como o Brasil, onde o investimento nos serviços relativos à informação espacial é escasso, as informações geográficas voluntárias também são interessantes alternativas para incrementar a velocidade de atualização cartográfica, pois são de livre acesso e constantemente revisadas. Neste contexto, a Infraestrutura Nacional de Dados Espaciais do Brasil (INDE-BR), no seu papel de facilitar e ordenar o acesso às bases de dados espaciais oficias, também pode se beneficiar do uso de informações prestadas por usuários voluntários na tarefa de enriquecer o conjunto de dados disponível em seu banco. Dessa maneira, elaborou-se o presente artigo, no qual investiga-se a compatibilidade das informações geográficas voluntárias com o perfil de metadados oficial do Brasil, adotado na estruturação da INDE-BR. Para tanto, foram selecionados sistemas de informações geográficas voluntárias os quais tiveram seus metadados analisados e comparados aos padrões adotados no documento Perfil de Metadados Geoespaciais do Brasil. Dos resultados, pode-se dizer que os padrões adotados pelo sistema OpenStreetMap são compatíveis com o padrão adotado pelo Perfil MGB. Esse resultado aponta para a necessidade de se investigar as informações geográficas voluntárias para que se tenha mais uma 
potencial ferramenta a favorecer o crescimento social, econômico e político de uma nação, assim como o Brasil.

Palavras-chave: Perfil de Metadados Geospaciais do Brasil, Informações Geográficas Voluntárias, Infraestrutura Nacional de Dados Espaciais do Brasil.

\begin{abstract}
:
In the last few years, researchers and mapping agencies have investigated the Volunteered Geographic Information aiming to comprehend how VGI systems could provide information for official databases. For example, Brazil has scarce investments on the field of geoinformation production and, in this case, the volunteered geographic information could be an alternative to increase the speed of geoinformation updating process. For this reason, we have designed this research in order to investigate the compatibility of Volunteered Geographic Information metadata with the Official Brazilian Geospatial Metadata Profile. Therefore, we have selected VGI systems as well as a set of information and proceeded to the comparison of the Brazilian geometadata profile with the chosen VGI content. The results have suggested there is a similarity between the official profile and the metadata available within the evaluated VGI systems. In general, the foregoing results have indicated the need of further studies on assessing VGI content for several purposes, especially on those relative to official database updating, because this volunteered information could promote social, economic and political development of certain regions in which there are not updated geoinformation available, like occurs in Brazil.
\end{abstract}

Keywords: Brazilian Geospatial Metadata Profile, Volunteered Geographic Information, Brazilian Spatial Data Infrastructure.

\title{
1. Introdução
}

Um indivíduo que não tem acesso às informações concernentes a seu próprio território é, sobremaneira, alienado aos seus direitos (Sluter, 2013). Resguardo constitucional para com o direito à cidadania (Brasil, 1988), é dever do Estado prover ao cidadão informações sobre o território onde este vive. Entretanto, no contexto brasileiro, a falta de investimento em políticas que ofereçam bases cartográficas atualizadas torna-se empecilho ao pleno desenvolvimento da cidadania e, também, do próprio país (Sluter, 2013). Nesse sentido, segundo Camboim e Sluter (2009), o Brasil encontra-se quase integralmente na escala de 1:250.000, sendo que, as atividades relacionadas ao planejamento e ordenamento do espaço dependem de mapas em escalas maiores. Por esse motivo, existem problemas para a execução das políticas de Estado concernentes ao planejamento e ordenamento do território como, por exemplo, a identificação de áreas de risco à ocupação humana e a promoção de obras de infraestrutura (Bravo e Santil, 2013).

Entretanto, observa-se que, nos últimos anos, cresceu a preocupação das autoridades brasileiras para com o desenvolvimento de uma cartografia nacional adequada às necessidades de seus cidadãos. Indicativo da importância que se tem dado à construção do mapeamento de base, é demonstrado pela inserção de instrumentos normativos no foro legal da estruturação da cartografia de base nacional. Na esfera federal, é dever da União "organizar e manter os serviços oficiais de estatística, geografia, geologia e cartografia de âmbito nacional” (Brasil, 1988). 
Segundo o Decreto s/n de $1^{\circ}$ de agosto de 2008, compete à Comissão Nacional de Cartografia subsidiar a formulação de ações que envolvam Cartografia, no território brasileiro (Brasil, 2008). Frente aos desafios tecnológicos, é também designada à CONCAR a tarefa de promover "meios para atender às novas demandas, incorporar capacidades e tecnologias, bem como promover a qualidade e integração dos serviços e produtos cartográficos" (Concar, 2010). Cabe, portanto, a este organismo público o provimento do aperfeiçoamento, tecnológico e metodológico, que aprimore o desenvolvimento do Sistema Cartográfico Nacional. Entretanto, essas inciativas pontuais não ofereceram, até então, respaldo para o desenvolvimento de um mapeamento de base completo (Camboim e Sluter, 2009).

Contudo, ainda há certa quantidade de problemas a serem resolvidos (Camboim e Sluter, 2009; Mendonça e Sluter, 2011; Bravo e Santil, 2013), os quais relacionam-se diretamente com a falta de investimentos públicos para subsidiar projetos de melhoramento do mapeamento de base do Brasil, assim como fora incitado pelas discussões de Estes e Mooneyhan (1994). Ratifica-se, então, a importância da existência de pesquisas científicas que contribuam de modo a subsidiar suporte de conhecimento indispensável ao desenvolvimento de soluções que comportem as necessidades do desenvolvimento de uma cartografia nacional contínua e atualizada. (Bravo e Santil, 2013). Além disso, esse desenvolvimento precisa ancorar-se nas necessidades dos indivíduos que coabitam a atual sociedade, uma vez que aproximar as soluções com o cotidiano das pessoas é, sobremaneira, convidativo ao sucesso desta ou daquela tecnologia (Castells, 2003).

Á luz desses fatos, observa-se que a participação dos indivíduos inseridos na sociedade, em seus diversos estratos, é uma tendência natural promovida pelo momento tecnológico em que se vive (Castells, 2003; Borba et al, 2012). Além disso, no que se refere à produção de dados espaciais, as IDEs (Infraestrutura de Dados Espaciais) têm se mostrado importantes plataformas para a produção e disseminação de informações oficiais, de um modo mais aberto e, talvez, colaborativo (Borba et al, 2012; Camboim, 2013). Analogamente, em virtude da demanda atual por participação dos usuários na produção e disseminação do conteúdo disponível na internet (Cormode e Krishnamurthy, 2008), alternativas como a das Informações Geográficas Voluntárias têm figurado no cenário das pesquisas científicas em Cartografia como fonte paralela à atualização dos bancos de dados oficiais (Bearden, 2007; Anand et al, 2010), por estarem disponíveis em plataformas web de livre acesso, assim como as IDEs.

Os sistemas de Informações Geográficas Voluntárias ofertam informações atualizadas e feitas de forma voluntária, i.e., a licença de uso é gratuita. Equacionando-se o problema de confiabilidade (Flanagin e Metzger, 2008), pode-se promover a integração desses dados com as bases oficiais, o que faria com que o acesso à informação cartográfica fosse condizente com a demanda atual da sociedade brasileira. Por exemplo, a Infraestrutura Nacional de Dados Espaciais do Brasil (INDE-BR) (Brasil, 2008), no seu objetivo de atuar na geração e compartilhamento de dados espaciais, insere-se no contexto de organismos oficiais os quais seriam, sobremaneira, favorecidos em utilizar de informações espaciais prestadas por usuários voluntários, uma vez que tal prática enriqueceria o conjunto de dados espaciais disponível em seu banco. No entanto, países nos quais os problemas relativos à atualização e abrangência do mapeamento sistemático em escalas adequadas, tais ideias ainda são quase inatingíveis. Por exemplo, o Brasil, ainda travado no crescimento de determinados setores, sente, por vezes, a falta que faz conhecer o próprio território (Sluter, 2013). Talvez por esse motivo tem se pensado em iniciativas colaborativas como o Programa Nacional de defesa civil ou mesmo as ações normativas integradoras da já citada Infraestrutura Nacional de Dados Espaciais, a INDE-BR. Porém, tais iniciativas são incipientes quando comparadas às norte-americanas (Bearden, 2007) e britânicas (Haklay, 2010; Anand et al, 2010). 
É por esse motivo que a presente pesquisa foi idealizada, à guisa de se estudar a possibilidade de integração entre as informações espaciais oficiais e aquelas elaboradas por voluntários, postadas nos sistemas de informação geográfica frutos da era dos usuários produtores ou "produsers" (Budhathoki et al, 2008). Contudo, para se integrarem aos padrões definidos para a INDE-BR, sabe-se que as informações voluntárias precisam ser avaliadas segundo a adequação dos dados existentes e seus parâmetros de qualidade ao uso pretendido e, entre os documentos que fornecem as diretrizes para tal padronização está o "Perfil de Metadados Geoespaciais do Brasil (Perfil MGB)", perfil nacional oficial da norma internacional ISO:19115. Assim, entende-se que há um interesse público em como aproveitar a informação voluntária, editada por cidadãos brasileiros, no contexto da infraestrutura de dados espaciais brasileira. Logo, há uma necessidade de se investigar como é possível compatibilizar as informações destas feições geográficas - fruto da utilização dos sistemas de informação geográficas voluntárias - com o perfil MGB, uma vez que há no cerne da informação geográfica voluntária, uma característica de descrição da informação já em níveis de conhecimento. Tal característica torna possível a compatibilização com o mecanismo de metadados oficial, além de aproximar os interesses e necessidades dos usuários com as funcionalidades do sistema de informações geográficas voluntário.

Nesse contexto, pode-se dizer que o objetivo geral deste artigo é o de demonstrar a compatibilidade do padrão de metadados adotados em sistemas de informações geográficas voluntárias com aquele adotado na INDE-BR. Nos tópicos que seguem apresenta-se conceitos relativos à produção da informação espacial no Brasil e a modalidade web para a disseminação do conteúdo geográfico oficial do país, a INDE-BR. Logo após, desenha-se o cenário relativo à produção de informações geográficas de forma voluntária para que seja viabilizada a criação de uma atmosfera de conhecimento propícia à discussão do ponto central deste trabalho. Nos tópicos subsequentes, tem-se a metodologia empregada para o desenvolvimento deste artigo, os resultados e discussões concernentes à aplicação da metodologia proposta, bem como, as conclusões sobre o assunto abordado.

\section{Produção da Informação Espacial no Brasil}

A produção da informação espacial brasileira sofreu e sofre, desde o início da implantação do sistema cartográfico nacional, com as mazelas evocadas pela não priorização do ato de conhecer o próprio território. As agências oficiais de mapeamento brasileiras, a saber o Diretoria de Serviço Geográfico do Exército Brasileiro - DSG - e o Instituto Brasileiro de Geografia e Estatística - IBGE - não recebem aporte financeiro suficiente para manter uma cartografia nacional homogênea, articulada e, principalmente, contínua (Camboim e Sluter, 2009). Por exemplo, ao se observar uma série histórica dos investimentos feitos nos últimos três anos, segundo aquilo que foi promulgado na lei orçamentária brasileira de 2012, 2013 e 2014, pode-se perceber os problemas que acometem a cartografia nacional oficial. Segundo o relatório orçamentário do Ministério de Planejamento, Orçamento e Gestão, em 2012 e 2013 a Fundação Instituto Nacional de Geografia e Estatística recebeu do governo federal brasileiro 1,6 bilhões de reais, para cada um dos anos, respectivamente. Essa quantia foi dissolvida para o pagamento de funcionários, compra de material básico, manutenção das dependências e também, para o investimento nas pesquisas e atualização dos programas. O programa de "Pesquisas, Estudos e Levantamentos Geocientíficos" do referido instituto, no qual encaixam-se os programas de 
provimento e atualização do mapeamento de base recebeu o aporte de 4,2 milhões de reais no ano de 2013 (0,26\% do valor total destinado ao IBGE no ano de 2013) e 4,8 milhões de reais no ano de 2014 (0,22\% do valor total destinado ao IBGE no ano de $2014-2,1$ bilhões de reais).

Nesse contexto, pode-se perceber que apesar do crescimento aparente dos valores destinados ao instituto e aos programas que cuidam do mapeamento de base brasileiros, a porcentagem relativa daquilo que tais programas recebem em relação ao valor total do orçamento do IBGE, ainda são significativamente baixos. Entretanto a situação mais detalhada permite revelar uma situação pouco mais caótica. No ano de 2012 dos 1,6 bilhões de reais investidos no IBGE, apenas 352 mil reais foram destinados à atualização da base contínua e 1,5 milhões de reais no item "mapeamento terrestre e de referência" (Brasil, 2012; Brasil, 2013; Brasil 2014). Esse é o típico quadro de países considerados em desenvolvimento, os quais são demasiadamente avassalados por problemas de gestão e cuidados com a infraestrutura (Estes e Mooneyhan, 1994)

Entretanto, quando se pensa na esfera privada, sabe-se que o desenvolvimento da tecnologia computacional e o contínuo interesse dos indivíduos em utilizar mapas para as mais diversas finalidades, favoreceu a disseminação do uso da cartografia no cotidiano das pessoas e, por conseguinte, fez surgir o interesse de grandes empresas de Tecnologia da Informação (e.g., Google e Microsoft) no segmento espacial. Além disso, a popularidade e a continua expansão destes sistemas com inclusão de dados 3D, fotos, StreetView e aplicativos, tem ratificado a indicação de intensa demanda por este tipo de informação.

Não aquém deste cenário e não diferente das grandes empresas privadas, os governos dos países pelo mundo começaram a ver o potencial de se produzir e disseminar os produtos de geoinformação com o apoio de plataformas web, já no início da década de 1990. Neste caso, consideradas "ações de boa governança" (Concar, 2010) as IDEs têm servido populações de diversos países de modo a facilitar o acesso à geoinformação.

\subsection{A Infraestrutura Nacional de Dados Espaciais e o Perfil de Metadados Geoespaciais do Brasil}

Na última década, houve um crescente interesse na utilização de plataformas web para a disseminação de informações geográficas; inclui-se neste grupo, até mesmo, os órgãos públicos (Johnson e Sieber, 2012; Camboim, 2013; Camboim e Sluter, 2013). As plataformas para a disseminação deste tipo de conteúdo podem ser chamadas Infraestruturas de Dados Espaciais (IDE) quando configuradas como "rede dinâmica composta de pessoas, dados, políticas, padrões e tecnologia para utilização melhorada de dados e serviços espaciais dentro da jurisdição de um país" (Grus, et. al., 2006).

As IDEs surgiram no cenário de crescente disponibilidade de dados espaciais e tornaram-se grandes facilitadoras do acesso democratizado a esse conteúdo (Camboim e Sluter, 2013). A dinâmica a envolver o concebimento dessas estruturas, motivou, também, a evolução de seus elementos com base na modificação constante dos conceitos os quais permeiam sua plataforma de apresentação: a web. A Figura 1, adaptada de Camboim e Sluter (2013), ilustra o caminho pelo qual trilhou-se essa remodelagem. Nela pode-se observar que, num primeiro momento, as IDEs, segundo os moldes da WEB 1.0 (Cormode e Krishnamurthy, 2008), eram estruturas centralizadas e com foco nos dados. Ao passo que as estruturas web modificaram-se, as IDEs 
evoluíram e conseguiram alcançar a descentralização. Além disso, aproximaram-se dos usuários que passaram a interagir com mais frequência com os sistemas disponíveis na web e, por vezes, produzir dados para publicação.

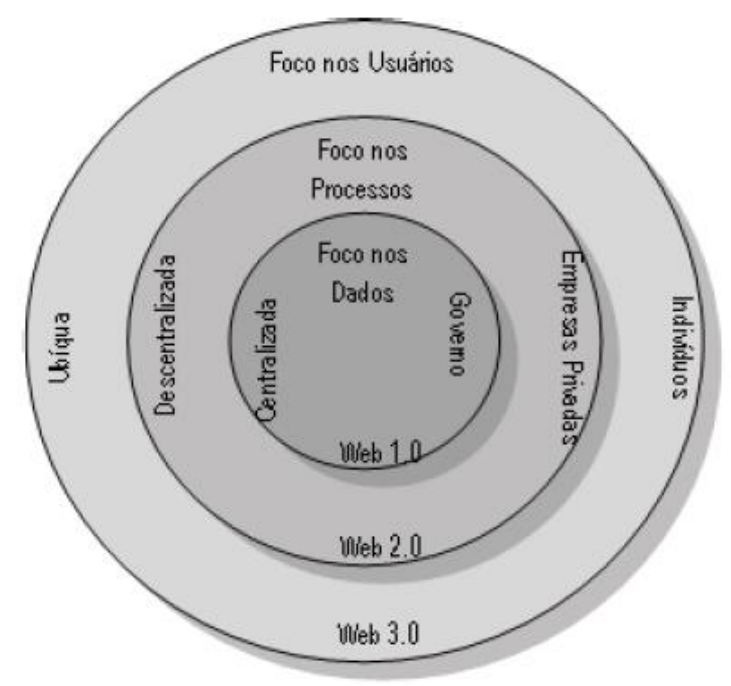

Figura 1: Evolução das IDEs e conceitos WEB. Fonte: Camboim e Sluter, 2013.

Assim como apresentado na Figura 1, pode-se dizer que as IDEs estruturam-se em vários níveis, os quais dimensionam o alcance de sua jurisdição. Entretanto, todos os níveis são interdependentes no que se refere à legislação e alimentação. Ao passo que a legislação dos níveis superiores impera na construção dos níveis inferiores, é na camada mais baixa que há grande alimentação de toda a estrutura de IDEs. Nesse sentido, é necessário haver iniciativas em todas as frentes, sejam elas superiores, sejam elas inferiores, para que se crie uma plataforma homogênea. No Brasil, por exemplo, há iniciativas nos estratos superiores, como a Infraestrutura Nacional de Dados Espaciais do Brasil (Brasil, 2008), mas pouco se faz nas camadas inferiores. Neste último campo, destacam-se, apenas, iniciativas que intencionam estabelecer IDEs locais como, por exemplo, as de universidades, ambientes nos quais estarão disponíveis informações concernentes ao ambiente acadêmico (planta, ensalamento, jurisdição) para todo e qualquer indivíduo que deseja navegar por estes locais.

Dessa maneira, segundo as características apresentadas, entende-se que a criação de uma Infraestrutura Nacional de Dados Espaciais é iniciativa de suma importância para o desenvolvimento de um Mapeamento Básico de Referência eficaz e robusto (Camboim e Sluter, 2013). Não obstante, é também um veículo que permite acesso à informação espacial oficial de maneira a atender as necessidades de uma população cada vez mais engajada no uso e produção de geoinformação.

Não longe, o governo brasileiro, apesar de todo o descuido para com o mapeamento oficial de seu território, instituiu, por intermédio do Decreto $n^{\circ}$ 6666, de 27 de novembro de 2008, a INDEBR. Segundo a redação desta norma, a implantação da Infraestrutura Nacional de Dados Espaciais do Brasil tem como principais objetivos (Brasil, 2008):

I. promover o adequado ordenamento na geração, no armazenamento, no acesso, no compartilhamento, na disseminação e no uso dos dados geoespaciais de origem federal, estadual, distrital e municipal, em proveito do desenvolvimento do País;

II. promover a utilização, na produção dos dados geoespaciais pelos órgãos públicos das esferas federal, estadual, distrital e municipal, dos padrões e normas homologados pela Comissão Nacional de Cartografia - CONCAR; e

Bol. Ciênc. Geod., sec. Artigos, Curitiba, v. 21, no 3, p.465- 483, jul-set, 2015. 
III. evitar a duplicidade de ações e o desperdício de recursos na obtenção de dados geoespaciais pelos órgãos da administração pública, por meio da divulgação dos metadados relativos a esses dados disponíveis nas entidades e nos órgãos públicos das esferas federal, estadual, distrital e municipal.

Ao se observar tais objetivos, pode-se perceber que há intenção de se melhorar o cenário cartográfico nacional, apresentado anteriormente. Entretanto os desafios são muitos e eles perpassam pela integração de iniciativas oficiais, como os marcos normativos e, também, pela parcela da sociedade, materializada em ações como as pesquisas científicas e pela própria contribuição dos indivíduos usuários. Além disso, para a implantação da INDE-BR com todo seu arcabouço de objetivos, é necessário que se crie padrões para que o repositório de dados receba as informações de maneira ordenada e consistente. Desse modo, a comissão responsável pela implantação da INDE-BR, a CONCAR, adotou padrões, tanto para os dados quanto para os metadados que adentrarão à plataforma oficial, os quais são alinhados aos padrões internacionais estabelecidos por instituições como a ISO/TC211 (International Organization for Standarization) e OGC (Open Geospatial Consortium). Essas são duas vertentes as quais merecem grande atenção para o desenvolvimento de uma IDE organizada e adequada ao uso. Entretanto, à guisa do interesse desta pesquisa, dar-se-á maior atenção ao perfil de metadados a ser adotado na implantação da INDE-BR.

Nesse sentido, o Perfil de Metadados Geoespaciais do Brasil, o Perfil MGB, é o documento produzido em função das necessidades de se padronizar os metadados das informações coletadas em campo, as quais comporão a base de dados oficial do Brasil, disseminada pelo sistema da INDE-BR. Ele é fruto das discussões do grupo de trabalho em "Dados e Metadados", formado por profissionais envolvidos no CEMG - Comitê de Estruturação de Metadados Geoespaciais — que é o organismo responsável pela implantação do Perfil MGB.

Segundo o Plano de Ação para a implantação da INDE-BR (Concar, 2010), a definição mais simples de metadados é aquela que exprime que são "os dados que descrevem os dados". Sabese que essas informações reúnem conteúdo necessário "para que os dados se tornem úteis", ao uso. A função de se trabalhar com metadados é, também, simples, pois tal conteúdo ajuda nas tarefas de documentação e organização dos dados provenientes das diferentes fontes, captados por diferentes sistemas em regiões distintas (Brasil, 2010). Dessa maneira, para que algum dado espacial seja compartilhado na plataforma da INDE-BR, este deve ser modelado segundo o perfil de metadados geoespaciais. Por este motivo, nesta investigação, utilizou-se do documento Pefil MGB como marco balizador à manobra de comparação da compatibilidade de informações geográficas voluntárias com os requisitos à participação destas últimas no quadro de possíveis alternativas à atualização do BDG (Banco de Dados Geográfico) oficial. Assim sendo, abre-se caminho para apresentação dos conceitos os quais permeiam tanto as IGV (Informações Geográficas Voluntárias), quanto os sistemas web para a disseminação deste tipo de conteúdo. 


\section{As Informações Geográficas Voluntárias e o Perfil de Metadados Geoespaciais do Brasil}

A materialização da visão humana sobre os fenômenos espaciais atingiu interatividade nunca antes vista: o que antes era representado apenas por profissionais como os engenheiros, arquitetos, geógrafos, pode ser, agora, objeto subordinado às conceitualizações leigas. Não longe, as convenções não mais se aplicam à dinâmica desses novos ambientes: os usuários da informação espacial podem também, recriar e representar o mundo, à sua maneira.

Goodchild (2007) afirma que esse acontecimento fatídico é um fenômeno web, ocasionado pelo desejo dos próprios indivíduos em compartilhar seu conhecimento. Haklay (2010) buscou compreender melhor os impactos gerados por tal fenômeno, no que se conhece sobre a avaliação da qualidade da informação espacial; Coleman et al (2009) buscaram saber qual sentimento a encorajar a prática do "compartilhar voluntariamente"; o Serviço Geológico Americano (USGS) enxergou nessa fonte, suprimento à atualização de suas bases cartográficas; Zook et al (2012) mostraram uma aplicação de cunho altruísta para aquilo que Goodchild (2007) chamou de Volunteered Geographic Information (VGI), ou, Informação Geográfica Voluntária (IGV).

De fato, os Sistemas de Informações Geográficas Voluntárias revolucionaram a maneira de se pensar cartografia (Goodchild, 2007). Mas não é de todo um elemento surpresa na história de uma ciência incipiente apenas por força de um marco tardio (Löbben, 2004). Há tempos que as revoluções conceituais acontecem nos campos de conhecimento relativos à cartografia e muito disso se deve à interdisciplinaridade e à proximidade com o cotidiano dos indivíduos no uso de seus produtos, os mapas (Kitchin e Dodge, 2007; Elzakker, 2004).

Mas não só em revoluções conceituais que construiu-se aquilo que se chama de "cartografia enquanto ciência" ou "ciência da cartografia" (Harley, 1990). Muito embora os conceitos sejam importantes alicerces do conhecimento, a cartografia como uma grande área das geociências, apoiou-se, também, no empirismo desbravador de proeminentes visionários, cartógrafos ilustres, como Arthur Robinson e Jacques Bertin (Robinson, 1952; Bertin, 1983; Shirreffs, 1992; Maceachren, 1995). Assim, talvez, fora construído o outro grande arcabouço de conhecimento que fez florescer a moderna visão de uma cartografia mais próxima às pessoas comuns, como aquela acima indicada, a dos voluntários (Goodchild, 2007; Haklay, 2010; Budhatoki et al, 2008; Liu e Palen, 2010; Zook et al, 2012; Heipke, 2010)

Interessantemente, a falta de conhecimento formal não condenou o uso desse tipo de informação (voluntária) em aplicações oficiais (Haklay, 2010; Bearden, 2007). Não só o Serviço Geológico Americano, por intermédio do projeto "The National Map Corps" (Bearden, 2007), mas também o Ordnance Survey - outra grande agência de mapeamento radicada em território britânico - têm visto com "bons olhos" o segmento crowdsourced dos mapas (Anand et al, 2010).

A riqueza das informações geográficas voluntárias relaciona-se com o poderio de mudanças presente no voluntariado, não só pela quantidade de informações produzidas, mas também, pela particularidade de permitir-se que indivíduos dessa ou daquela localidade criem e recriem o espaço geográfico no qual estão inseridos, à sua maneira (Mummidi e Krumm, 2008; Leeuw et al, 2011; Goodchild, 2007). Dessa maneira, entende-se que o sentimento sobre o lugar, i.e., a "topofilía" de Tuan (1991), evoca novos ares à concepção de uma cartografia mais próxima ao usuário (Kitchin e Dodge, 2007), capaz até de enriquecer as bases oficiais, como é o caso da própria INDE-BR, ou mesmo, de pequenas parcelas de sua concepção, o Perfil MGB.

Pensar na entrada de Informações Geográficas Voluntárias na dimensão oficial (Johnson e Sieber, 2012), não é um desserviço à promoção de uma cartografia nacional radicada em bases Bol. Ciênc. Geod., sec. Artigos, Curitiba, v. 21, no 3, p.465- 483, jul-set, 2015. 
científicas consolidadas. É sim necessidade de primeira ordem para que se interliguem diversos setores da sociedade e, também, para que se compreenda as necessidades dos usuários a quem foram idealizadas as plataformas, as camadas de informações, ou as próprias categorias para consulta à informação. Nesse sentido, entende-se que os sistemas VGI têm potencial positivo no que se refere aos aspectos mais subjetivos da idealização desse tipo de solução (uma IDE), como é o caso acima explicitado da definição de um perfil de metadados que atenda às necessidades de todos os usuários da plataforma.

Entretanto, há ainda a necessidade de que se estabeleçam métricas e mecanismos de verificação, de forma que se possa avaliar não só a completude dos metadados em sistemas de informação geográfica voluntários, mas também todo o conjunto que caracteriza tais dados: qualidade geométrica - em referência à escala de utilização; qualidade de atributos tanto em relação às características semânticas quanto em relação à acurácia; e todas estas métricas em relação à temporalidade (Haklay, 2010; Flanagin e Metzger, 2008).

Por esses motivos e outros tantos expostos, idealizou-se um processo descrito no item subsequente, o qual permitiu que se avaliasse a compatibilidade das informações voluntárias com o Perfil MGB, para que se tenha, futuramente, uma alternativa à atualização e à idealização de plataformas de disseminação do conteúdo geográfico, como a INDE-BR.

\section{Metodologia}

Para a condução do presente trabalho, buscou-se cumprir etapas as quais estão sumarizadas no fluxograma da Figura 2. Nele apresentam-se os itens que foram idealizados segundo as intenções da proposta aqui apresentada.

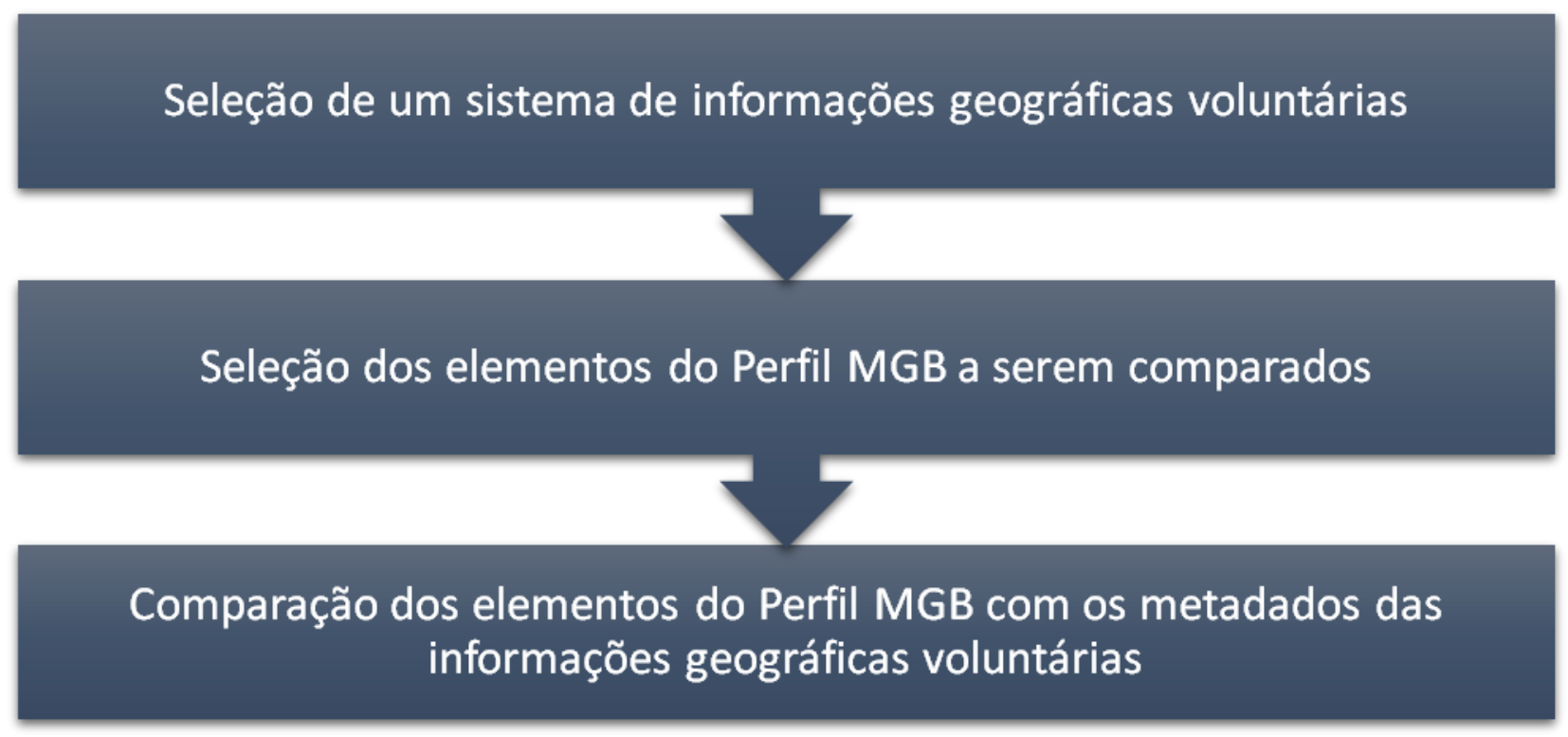

Figura 2: Evolução das IDEs e conceitos WEB. Fonte: Camboim e Sluter, 2013. 
Dessa maneira, apresentado o fluxograma o qual guiou a incursão desta investigação, nos itens que seguem descrevem-se os critérios utilizados para dar andamento a cada uma das etapas elencadas na Figura 2.

\subsection{Seleção de sistemas de Informações Geográficas Voluntárias}

A seleção de sistemas de Informações Geográficas Voluntárias que satisfizessem as necessidades desta investigação foi feita segundo um estudo preliminar, no qual intencionou-se conhecer características das plataformas VGI disponibilizadas na internet. Dessas características, procurou-se pinçar aquelas que estivessem de acordo com as premissas deste trabalho, i.e., que permitissem acesso aos metadados de maneira clara e organizada. Isso, pois, preconizou-se em evitar descaminhos os quais impossibilitassem efetivas comparações entre as componentes dos metadados. Além deste primeiro critério, buscaram-se sistemas os quais tivessem, minimamente, quantidade de usuários significativa, isto é, sistemas VGI que tivessem grande aporte de usuários para que fosse ampliado o impacto das discussões e para que fossem mantidas as proporções entre o sistema VGI selecionado e as dimensões de uma IDE como a INDE-BR. Os sistemas que atenderam a esses critérios foram o OpenStreetMap, o Wikimapia e o Google Maps.

Nesse sentido, após selecionados os sistemas balizadores da comparação, procurou-se identificar elementos do Perfil MGB os quais serviriam como base à comparação. Os critérios relativos à seleção destes elementos estão descritos no item que segue.

\subsection{Seleção dos elementos do Perfil MGB}

Tendo em vista a intenção de se comparar a compatibilidade das informações geográficas voluntárias com o Perfil MGB, encontrou-se no documento elaborado pelo Comitê de Estruturação de Metadados Geoespaciais (CEMG), o Perfil de Metadados Geoespaciais do Brasil (2009), suporte ao encaminhamento desta investigação.

Nesse documento estão dispostos os elementos estruturantes do perfil de metadados a serem adotados na padronização da Infraestrutura Nacional de Dados Espaciais do Brasil, pensados segundo os padrões da ISO:19115. A Tabela 1 apresenta o perfil MGB sumarizado. 
Tabela 1: Elementos do Perfil MGB

\begin{tabular}{r|c}
\hline \multicolumn{1}{|c|}{ Entidades/Elemento } & Obrigatoriedade \\
\hline Datulo & Obrigatório \\
\hline Responsável & Obrigatório \\
\hline Obrigatório \\
\hline Idioma & Obrigatório \\
\hline Código de Caracteres do CDG & Condicional \\
\hline Categoria Temática & Obrigatório \\
\hline Resolução Espacial & Opcional \\
\hline Resumo & Obrigatório \\
\hline Formato de Distribuição & Obrigatório \\
\hline Extensão Temporal e Altimétrica & Opcional \\
\hline Tipo de Representação Espacial & Opcional \\
\hline Sistema de Referência & Obrigatório \\
\hline Linhagem & Opcional \\
\hline Acesso Online & Opcional \\
\hline Identificador Metadados & Opcional \\
\hline Nome Padrão de Metadados & Opcional \\
\hline Versão da Norma de Metadados & Opcional \\
\hline Idioma dos Metadados & Condicional \\
\hline Código de Caracteres dos Metadados & Condicional \\
\hline Responsável pelos Metadados & Obrigatório \\
\hline Data dos Metadados & Obrigatório \\
\hline Status & Obrigatório \\
\hline
\end{tabular}

Na Tabela 1, pode-se perceber que há três classes de elementos as quais permitem diferenciá-los quanto sua importância na implantação do Perfil MGB. Entendeu-se que, dos elementos constituintes desta proposta, apenas aqueles considerados obrigatórios e/ou condicionais, devem ser vistos como fundamentais à concepção de um perfil de metadados básico.

Por conseguinte, selecionados os sistemas VGI e os elementos do perfil de metadados oficial do Brasil a serem comparados, a etapa que seguiu foi a da efetiva comparação entre tais informações. $\mathrm{O}$ item que segue busca esclarecer os critérios adotados para que fosse feita tal análise.

\subsection{Comparação dos elementos do Perfil MGB com dados extraídos do sistema VGI selecionado}

Nesta última etapa, comparou-se as características dos metadados de informações disponibilizadas nas plataformas VGI selecionadas com os elementos do Perfil MGB os quais foram considerados importantes na avaliação. Tal comparação seguiu uma sequência elaborada na intenção de se descobrir qual dos sistemas poderia se encaixar melhor no perfil de um possível fornecedor de dados suplementares às bases cartográficas brasileiras, segundo aquilo que é preconizado no documento Perfil de Metadados Geoespaciais do Brasil. O indicativo de Bol. Ciênc. Geod., sec. Artigos, Curitiba, v. 21, no 3, p.465- 483, jul-set, 2015. 
maior compatibilidade dar-se-á pela quantidade de elementos em acordo com o proposto no perfil MGB.

Comparada a compatibilidade ao observar-se os elementos existentes nos metadados dos dados presentes nos sistemas VGI e com o Perfil MGB, a etapa que seguiu foi a de demonstração da potencialidade daquele que obteve maior congruência com os elementos obrigatórios e condicionais do referido documento. Essa demonstração foi feita de forma direta, por meio da seleção de uma feição de interesse, a qual foi escolhida por intermédio daquilo que se considerou possivelmente suplementar às informações contidas na base cartográfica oficial brasileira.

\section{Resultados E Discussões}

\subsection{Seleção de um Sistema de Informações Geográficas Voluntárias}

Partiu-se de um cenário o qual continha três grandes plataformas VGI: o Google Maps, o Wikimapia ${ }^{\circledR}$ e o OpenStreetMap. Dessas três plataformas optou-se pela não utilização do sistema da Google, uma vez que esta não é aberta e, também, não permite o acesso transparente às bases de dados modificadas.

Das plataformas VGI restantes, investigou-se a inserção dos sistemas Wikimapia® e OpenStreetMap na comunidade usuária do segmento voluntário dos mapas. Nesse sentido, averigou-se que tanto o Wikimapia ${ }^{\circledR}$ quanto o OpenStreetMap comportam as necessidades desta pesquisa, uma vez que atingiram quantidade de usuários superior a 1,5 milhões de indivíduos com cadastros ativos, bem como, grande quantidade de dados manipulados diariamente (OPENSTREETMAP, 2014; WIKIMAPIA®, 2014). Apesar de subjetivos, estes números representam usuários cadastrados com diversas nacionalidades, inclusive, a brasileira, condicionante sobremaneira interessante ao corpo desta investigação.

Adicionalmente, os sistemas Wikimapia ${ }^{\circledR}$ e OpenStreetMap permitem o acesso aos metadados das informações disponibilizadas em suas plataformas. Este último requisito corresponde àquele critério que ratificou a seleção destas plataformas web como bases à investigação das variáveis deste trabalho. Dessa maneira, o item que seguiu foi o da comparação entre os elementos do Perfil MGB e os metadados disponíveis nos sistemas VGI selecionados.

\subsection{Comparação dos elementos do Perfil MGB com os sistemas VGI selecionados}

Na Tabela 2, tem-se ilustrada a comparação entre os elementos condicionais e obrigatórios do Perfil MGB com aqueles elementos considerados de igual significado nos sistemas VGI selecionados. Eles foram pinçados por meio de incursões empíricas aos sistemas. 
Tabela 2: Comparação dos elementos do Perfil MGB com as entidades consideradas análogas nos sistemas VGI selecionados

\begin{tabular}{|c|c|c|}
\hline $\begin{array}{c}\text { Entidades e elementos obrigatórios do } \\
\text { Perfil MGB }\end{array}$ & $\begin{array}{c}\text { Campo correspondente no } \\
\text { Wikimapia } ₫\end{array}$ & $\begin{array}{c}\text { Campo correspondente no } \\
\text { OpenStreetMap }\end{array}$ \\
\hline Título & Título & Caminho \\
\hline Data & Histórico & Editado em \\
\hline Responsável & Histórico & Editado por \\
\hline Extensão Geográfica & Coordenadas - centro da feição & $\begin{array}{l}\text { Pontos - coord. dos pontos do } \\
\text { polígono }\end{array}$ \\
\hline Idioma & Idioma & etiqueta:LINGUA \\
\hline Código de Caracteres do CDG & aberto: $\mathrm{CM}$ /Usuários & aberto: taginfo \\
\hline Categoria Temática & Categorias - livre & Etiquetas - taginfo \\
\hline Resumo & Descrição & Comentário \\
\hline Formato de Distribuição & Wikimapia@ wiki & Openstreetmap wiki \\
\hline Sistema de Referência & Wikimapiaß wiki & Openstreetmap wiki \\
\hline Idioma dos Metadados & Idioma & nome:LINGUA \\
\hline Código de Caracteres dos Metadados & aberto: CM/Usuários & aberto: taginfo \\
\hline Responsávelpelos Metadados & Histórico & editado por: \\
\hline Data dos Metadados & Histórico & editado em: \\
\hline Status & Histórico & Editado em \\
\hline
\end{tabular}

Ainda na Tabela 2, pode-se perceber que apesar das diferentes denominações entre os elementos dos campos, os sistemas VGI selecionados atendem aos critérios de caracterização ou definição dos elementos obrigatórios e condicionais do Perfil MGB, no seu corpo documental. Ademais, observa-se que, por vezes, um mesmo elemento nos sistemas VGI pode descrever mais de um elemento do Perfil MGB, o que pode ser explicado pela simples diferença de estrutura adotada na concepção dos sistemas. É importante destacar, portanto, que dos elementos do Perfil MGB considerados obrigatórios e/ou condicionais é notável a compatibilidade na forma como os metadados são estruturados.

Nesse sentido, construiu-se a Tabela 3, na qual se tem a indicação de compatibilidade entre os Sistemas de Informações Geográficas Voluntárias selecionados e o perfil do MGB. A análise desta compatibilidade resultou na escolha do sistema OpenStreeMap para exemplos práticos de entidades e elementos do perfil MGB neste sistema, conforme etapa definida como demonstração da potencialidade do sistema.

Tabela 3: Comparação dos elementos do Perfil MGB com as entidades consideradas análogas nos sistemas VGI selecionados

\begin{tabular}{|c|c|c|}
\hline $\begin{array}{c}\text { Entidades e elementos obrigatórios do } \\
\text { Perfil MGB }\end{array}$ & Wikimapia ${ }^{\circledR}$ & OpenStreetMap \\
\hline Título & $\operatorname{sim}$ & $\operatorname{sim}$ \\
\hline Data & sim & sim \\
\hline Responsável & $\operatorname{sim}$ & $\operatorname{sim}$ \\
\hline Extensão Geográfica & não & sim \\
\hline Idioma & sim & $\operatorname{sim}$ \\
\hline Código de Caracteres do CDG & $\operatorname{sim}$ & $\operatorname{sim}$ \\
\hline Categoria Temática & $\operatorname{sim}$ & $\operatorname{sim}$ \\
\hline Resumo & $\operatorname{sim}$ & $\operatorname{sim}$ \\
\hline Formato de Distribuição & não & $\operatorname{sim}$ \\
\hline Sistema de Referência & $\operatorname{sim}$ & sim \\
\hline Idioma dos Metadados & $\operatorname{sim}$ & $\operatorname{sim}$ \\
\hline Código de Caracteres dos Metadados & $\operatorname{sim}$ & $\operatorname{sim}$ \\
\hline Responsável pelos Metadados & $\operatorname{sim}$ & $\operatorname{sim}$ \\
\hline Data dos Metadados & $\operatorname{sim}$ & $\operatorname{sim}$ \\
\hline Status & $\operatorname{sim}$ & $\operatorname{sim}$ \\
\hline
\end{tabular}

Bol. Ciênc. Geod., sec. Artigos, Curitiba, v. 21, nº 3, p.465- 483, jul-set, 2015. 
Ao se observar a Tabela 3, pode-se perceber que há um grau de compatibilidade das plataformas VGI analisadas com o Perfil MGB, assim como fora apontado pela análise descrita na Tabela 2. Entretanto, dadas as diferenças de gerenciamento e/ou estruturação dos dados, foi possível verificar que o sistema OpenStreetMap é o que teve maior congruência com as determinações do Perfil MGB. Esta plataforma atende a todos os critérios para preenchimento dos metadados obrigatórios e condicionais do perfil designado para os dados oficiais brasileiros. Nesse sentido, para que pudesse ser feito tal apontamento, comparou-se item a item os elementos inseridos nos campos dos sistemas VGI analisados. Desta forma pôde-se averiguar que os requisitos que determinaram o sistema de maior compatibilidade foram: a extensão geográfica e o formato de distribuição.

O elemento "extensão geográfica", no caso do sistema Wikimapia ${ }^{\circledR}$ mostrou-se em desacordo com as necessidades elencadas no Perfil MGB, pois, dadas as características desta plataforma, não é possível que seja recuperada a geometria original do objeto, segundo suas características reais de ocorrência (ponto, linha ou polígono). Neste caso, as feições de área, por exemplo, têm coordenadas projetadas no centro do objeto vetorizado, i.e., um polígono é transformado em um ponto projetado no seu centroide. Em contrapartida, o sistema OpenStreetMap permite que sejam identificadas as coordenadas dos vértices de cada ponto dos vetores inseridos na plataforma, o que facilitaria, sobremaneira, a interligação com um banco de dados geográficos o qual receberia dados com a geometria dos objetos correta, bem como, fidedigna ao depositório de origem.

No caso do elemento "formato de distribuição", este pode ser considerado primordial ao desenvolvimento de aplicações que visam interligar as plataformas, porque permite que o desenvolvedor utilize do serviço de disponibilização dos dados em uma determinada plataforma GIS. Neste sentido, o sistema OpenStreetMap permite ao usuário efetuar o download das informações de maneira direta, nos formatos XML, SHP, PDF, SVG e WMS, sendo que, este último é o padrão da OGC adotado oficialmente pela INDE-BR. Em contrapartida, o sistema Wikimapia ${ }^{\circledR}$ não permitiu ao usuário efetuar download das informações nele contidas. Apenas por intermédio de uma aplicação desenvolvida para ser utilizada em conjunto com o sistema Google Earth®, software da Google Inc., é que foi possível que fossem extraídas algumas das feições existentes no Wikimapia®. Ainda assim, não foi possível que se obtivesse os metadados das informações baixadas, o que inviabilizou, sobremaneira a utilização desse sistema em termos de compatibilização com o Perfil MGB.

Para finalizar as comparações, buscaram-se exemplos de metadados de uma feição considerada suplementar aos dados do mapeamento oficial brasileiro, o Parque do Ibirapuera, localizado na cidade de São Paulo, Brasil (Figura 3). A Tabela 4 sumariza aquilo que se obteve quando acessou-se os metadados da supracitada feição e o resultado com os elementos do Perfil MGB. 


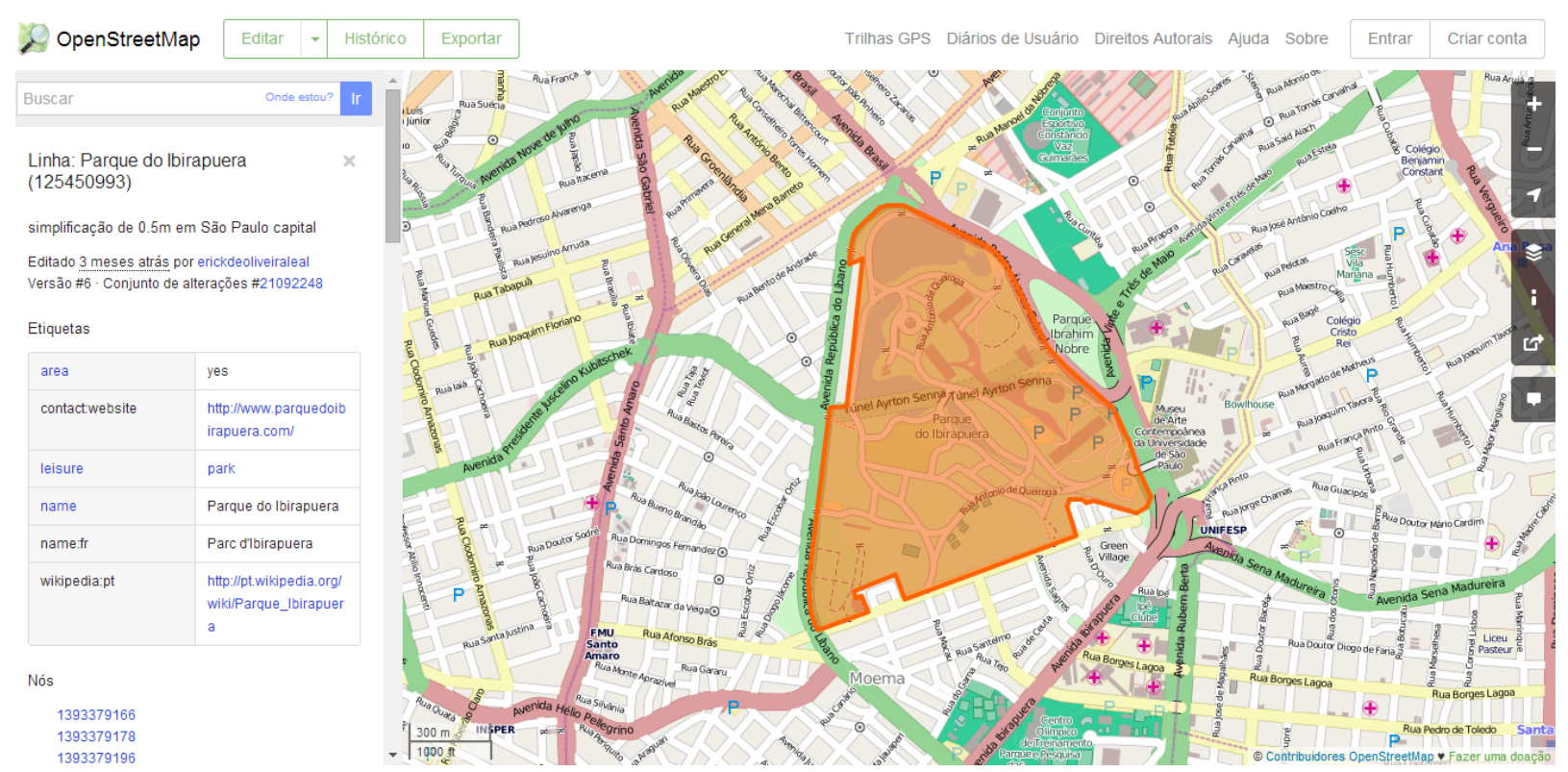

Figura 3: Acesso aos dados da feição "Parque do Ibirapuera" no sistema OpenStreetMap.

Tabela 4: Metadados da feição "Parque do Ibirapuera" no sistema OpenStreetMap

\begin{tabular}{c|c}
\hline Entidades e elementos obrigatórios do Perfil MGB & Openstreetmap exemplo \\
\hline Título & Parque do Ibirapuera \\
\hline Data & 3 meses atrás*** \\
\hline Responsável & Erickdeoliveiraleal \\
\hline Extensão Geográfica & área: $1393379166 ; \ldots ; 1393379166^{*}$ \\
\hline Idioma & pt; fr \\
\hline Código de Caracteres do CDG & parque \\
\hline Categoria Temática & wikipedia \\
\hline Resumo & XML, SHP, PDF, SVG e WMS \\
\hline Formato de Distribuição & WGS 84 \\
\hline Sistema de Referência & pt; fr \\
\hline Idioma dos Metadados & critério do usuário**** \\
\hline Código de Caracteres dos Metadados & erickdeoliveiraleal \\
\hline Responsável pelos Metadados & 3 meses atrás*** \\
\hline Data dos Metadados & ativo para consulta** \\
\hline Status &
\end{tabular}

* descritor dos nós de coordenadas, ao clicar nesses elementos as coordenadas são apresentadas. Quando se pensa na integração com um SGBD geográfico, essa informação será adicionada diretamente no campo correspondente à geometria da feição na tabela; ** se a feição aparece no sistema, o status é ativo para consulta; ***consulta feita no mês de novembro de 2013; **** o preenchimento desses itens fica a critério do formato que preferir o usuário.

Dessa maneira, ao se observar o exemplo apresentado (Tabela 4), percebe-se que há real possibilidade da utilização desses dados para que sejam preenchidos campos de metadados compatíveis com aqueles elencados no Perfil MGB, assim como defendeu-se nesta proposta de trabalho. Isso, pois, a estrutura de dados para quaisquer informações é a mesma dentro sistema OSM, i.e., qualquer dado advindo desta plataforma contém esses campos de metadados (preenchidos ou não). Cabe salientar que, quando baixadas, as informações geográficas contidas no sistema OSM apresentam os metadados por meio de uma estrutura de atributos, os quais compõem colunas de uma tabela. Esse conjunto de informações pode ser integrado a um SGBD geográfico para posterior manipulação. Todavia, apesar dessa aparente facilidade, é necessário sublinhar que, assim como fora afirmado anteriormente, há ainda necessidade de se avaliar a Bol. Ciênc. Geod., sec. Artigos, Curitiba, v. 21, no 3, p.465- 483, jul-set, 2015. 
qualidade dessas informações (Goodchild e Li, 2012) para que elas sejam consideradas adequadas à utilização nas plataformas oficiais, principalmente por conta daqueles campos os quais relegam-se totalmente aos critérios pessoais dos usuários, como os códigos de caracteres.

\section{Conclusões}

De todo o modo, entende-se que a proposta feita para o desenvolvimento desta investigação foi cumprida. Isso, pois, atingiu-se o objetivo de se qualificar a compatibilidade de informações geográficas voluntárias com o Perfil de Metadados Geoespaciais do Brasil. Para tanto, num primeiro momento, fez-se uma breve discussão a respeito dos conceitos que permeiam os campos de conhecimento relativos à produção da informação espacial oficial no Brasil. Logo em seguida, apresentou-se o conceito de informações geográficas voluntárias e discutiu-se elementos como a qualidade atrelada a esse tipo de informação, bem como a possibilidade paralela de utilização desse conteúdo na atualização de plataformas oficiais.

Da investigação proposta averiguou-se que há compatibilidade entre o Perfil MGB e aquilo que alguns sistemas VGI apresentam como metadados dos dados disponibilizados em suas plataformas. Dos sistemas analisados, destaque deve ser dado ao OpenStreetMap, plataforma livre, na qual obteve-se maior nível de compatibilidade com a plataforma oficial brasileira, a INDE-BR. Nesse sentido, é conveniente ressaltar a importância da obtenção de metadados atualizados, assim como aqueles obtidos nos sistemas VGI, os quais ajudam o usuário a avaliar a qualidade dos dados geoespaciais, para que então seja julgada a aptidão dos mesmos para o uso pretendido. Além disso, sublinha-se a importância das informações concernentes à linhagem dos dados que, apesar de não obrigatórios no Perfil MGB e de também não aparecerem nos sistemas VGI estudados, figuram na literatura (Guptill e Morrison, 1992) como essenciais para se conhecer a proveniência das informações espaciais, indicativo necessário para avaliação da qualidade de dados geográficos.

Entretanto, vale ressaltar que há a necessidade de equacionamento de diversos problemas, assim como aqueles observados no decorrer da elaboração deste estudo. Como sugestão de agenda para pesquisa, estas lacunas devem ser investigadas com mais propriedade em trabalhos futuros, a saber:

1. Como entender a distribuição espacial das atualizações nos sistemas VGI, para que possa ser fomentada a atualização em locais com alta demanda e baixa concentração de informações geográficas oficiais?

2. Como avaliar/documentar os parâmetros de qualidade neste processo?

3. Como observar questões legais sobre dados produzidos em ambiente não oficiais? Há necessidade/viabilidade de um processo de homologação? Quais os critérios poderiam ser utilizados?

4. Como automatizar a extração de metadados provenientes dos sistemas VGI?

Em suma, no desenvolvimento deste trabalho, ficou clara a importância da análise de ferramentas livres que possam contribuir na implantação de uma infraestrutura de dados nacional. Neste contexto, os usuários em geral podem constituir-se agentes da transformação de sua realidade, contribuindo para a visibilidade do seu território, suas riquezas e problemas, os

Bol. Ciênc. Geod., sec. Artigos, Curitiba, v. 21, no 3, p.465- 483, jul-set, 2015. 
quais devem ser analisados com cuidado pelo poder público. Desta maneira, a participação, como aquela presente nos sistemas VGI, deve ser melhor compreendida para que se tenha uma ferramenta inserida dentro dos preceitos previstos para a adoção crescente de metadados no Brasil.

\section{REFERÊNCIAS BIBLIOGRÁFICAS}

Anand, Suchith; Morley, Jeremy; Jiang, Wenchao; Du, Heshan; Hart, Glen; Jackson, Mike. "When worlds collide: combining Ordnance Survey and Open Street Map data". Artigo publicado nos Proceedings of AGI Geocommunity '10, London, UK, June 30, 2010.

Bearden, Morgan J. "The National Map Corps", Disponível em < http://www.ncgia.ucsb.edu/projects/vgi/docs/position/Bearden_paper.pdf >, acessado em abril de 2014.

Bertin, Jacques. Semiology of graphics. Traduzido por William J. Berg. London: The University of Wisconsin Press Ltd., 1983.

Borba, Rogerio L. R.; Strauch, Julia C. M.; Esteves, Maria Gilda P.; Souza, Jano. "INDE - Co: Infraestrutura Nacional de Dados Espaciais Colaborativa". Artigo publicado nos Anais de $1^{o}$ Seminário de Metodologia do IBGE e a XI Reunião IASI sobre Estatística Pública, Rio de Janeiro, RJ. 2012.

Bravo, João Vitor Meza; Santil, Fernando Luiz de Paula. "Avaliação da variação dos índices morfométricos a partir de dados extraídos de cartas topográficas e implicações para a leitura do risco a enchentes”. Revista Brasileira de Cartografia, 65 (2013): 939-949

Brasil. Ministério do Planejamento, Orçamento e Gestão. Orçamentos da União exercício financeiro 2014: projeto de lei orçamentária. Vol. IV, tomo II, 2014. Disponível em http://www.planejamento.gov.br/secretarias/upload/Arquivos/sof/ploa2014/VolumeIV_TomoII_ PLOA2014.pdf, acessado em abril de 2014.

Brasil, Ministério do Planejamento, Orçamento e Gestão. Orçamentos da União exercício financeiro 2013: projeto de lei orçamentária. Vol. IV, tomo II, 2013. Disponível em http://www.planejamento.gov.br/secretarias/upload/Arquivos/sof/ploa2013/Volume_4_Tomo_II. pdf, acessado em abril de 2014.

Brasil, Ministério do Planejamento, Orçamento e Gestão. Orçamentos da União exercício financeiro 2012: projeto de lei orçamentária. Vol. IV, tomo II, 2012. Disponível em http://www.planejamento.gov.br/secretarias/upload/Arquivos/sof/ploa2012/110831_ploa2012_v ol42.pdf, acessado em abril de 2014.

Brasil, Decreto $n^{\circ}$ 6666, de 27 de novembro de 2008. Institui, no âmbito do Poder Executivo federal, a Infra-Estrutura Nacional de Dados Espaciais - INDE, e dá outras providências. Brasília, DOU, 27 de novembro de 2008.

Brasil. Constituição da República Federativa do Brasil. Brasilia, 5 de outubro de 1988.

Budhathoki, Nama Raj; Bruce, Bertram; Nedovic-Budic, Zorica."Reconceptualizing the role of the user of spatial data infrastructure". GeoJournal, 72 (2008).

Camboim, Silvana Philippi. “Arquitetura para integração de dados interligados abertos à INDEBR”. Tese de doutoramento, Universidade Federal do Paraná, 2013. 
Camboim, Silvana Philippi; Sluter, Claudia Robbi. "Uso de ontologias para busca de dados geoespaciais: uma ferramenta semântica para a Infraestrutura Nacional de Dados Espaciais". Revista Brasileira de Cartografia, 65 (2013): 1127-1142

Camboim, Silvana Philippi; Sluter, Claudia Robbi. "The National Topographic Mapping as an indispensable database for a Brazilian National Spatial Data Infrastructure (NSDI)". Artigo publicado nos Proceedings of the 24th International Cartographic Conference, Santiago. Chile, 2009.

Castells, Manuel. A galáxia da internet: reflexões sobre a internet, os negócios e a sociedade. Traduzido por Maria Luiza X. de A. Borges. Rio de Janeiro: Jorge Zahar Ed. 2003.

Coleman, David; Georgiadou, Yola; Labonte, Jeff, "Volunteered Geographic Information: The nature and motivation of produsers". International Journal of Spatial Data Infrastructures Research, 4 (2009).

Concar. Legislação Cartográfica. 2010. Disponível em <www.concar.ibge.gov.br>, acessado em abril de 2013.

Concar, Comitê de Estruturação de Metadados Geoespaciais. Perfil de Metadados Geoespaciais $\begin{array}{llllll}\text { do Brasil } & \text { (Perfil } & \text { MGB). } & 2009 . & \text { Disponível } & \text { em }\end{array}$ $<$ http://www.concar.ibge.gov.br/arquivo/perfil_mgb_final_v1_homologado.pdf >, acessado em abril de 2014.

Cormode, Graham; Krishnamurthy, Balachander. "Key differences between Web 1.0 and Web 2.0". First Monday, 13 (2008).

Elzakker, Corneé P. J. M. van. "The Use of Maps in the Exploration of Geographic Data”. Tese de doutoramento, Netherlands Geographical Studies 326, ITC, 2004.

Estes, John E.; Mooneyhan, D. W. "Of Maps and Myths”. Photogrammetric Engineering and Remote Sensing, 60 (1994):517-524.

Flanagin, Andrew J.; Metzger, Miriam J. "The credibility of volunteered geographic information". GeoJournal, 72 (2008).

Goodchild, Michael F. "Citizens as sensors: the world of Volunteered Geography". GeoJournal, 69 (2007).

Goodchild, Michael F.; Li, Linna ."Assuring the quality of volunteered geographic information". Spatial Statistics, 1 (2012):110-120.

Grus, Lukasz; Crompvoets, Joep; Bregt, Arnold. "Defining National Spatial Data Infrastructures as Complex Adaptive Systems". Artigo publicado nos Proceedings GSDI-9 Conference, Santiago, Chile November 6-10, 2006.

Haklay, Mordechai. "How good is a Volunteered Geographical Information? A comparative study of OpeenStreetMap and Ordnance Survey datasets". Environmental Planning B, Planning Dev., 37 (2010).

Harley, John B. “Cartography, Ethics and Social Theory”. Cartographica, 27 (1990):1-23.

Heipke, Christian. "Crowdsourcing Geospatial Data". ISPRS Journal of Photogrammetry and Remote Sensing, 65 (2010).

ISO 19115:2014. Geographic Information - Metadata. International Organization for Standarization, 2014. 
Johnson, Peter A.; Sieber, R. E. "Motivations driving government adoption of the Geoweb". GeoJournal, 77 (2012).

Kitchin, Rob; Dodge, Martin. "Rethinking Maps". Progress in Human Geography, 31 (2007).

Leeuw, Jan De; Said, Mohammed; Ortegah, Lapezoh; Nagda, Sona; Georgiadou, Yola; DeBlois, Mark. "An assessment of the accuracy of Volunteered Road Map Production in Westerns Kenya”. Remote Sensing, 3 (2011):247-256.

Liu, Sophia B.; Palen, Leysia. "The New Cartographers: Crisis Map Mashups and the Emergence of Neogeographic Practice". Cartography and Geographic Information Science, 37 (2010).

Lobben, Amy K. "Tasks, strategies, and cognitive processes associated with navigational map reading: a review perspective". The Professional Geographer, 56 (2004):270-281.

Maceachren, Alan M. How maps work: representation, visualization, and design. New York: The Guilford Press, 1995.

Mendonça, André Luiz Alencar de; Sluter, Claudia Robbi. "Análise da relação entre o ensino e pesquisa em Ciências Geodésicas e a cobertura do mapeamento sistemático no Brasil". Revista Brasileira de Cartografia, 63 (2011):1-10.

Mummidi, Lakshmi Narayana; Krumm, John. "Discovering points of interest from users' map annotations". GeoJournal, 72 (2008):215-227.

Openstreetmap. Site <www.Openstreetmap.org>, acessado em abril de 2014.

Robinson, Arthur H. The Look of Maps. Madison: University of Wisconsin Press, 1952.

Shirreffs, W. S. "Maps as communication graphics". The Cartographic Journal, 29 (1992):3541.

Sluter, Claudia Robbi. “Território”. In Brasil em números. IBGE. Rio de Janeiro, 21 (2013).

Tuan, Y-Fu. "Language and the making of place: a narrative-descriptive approach". Annals of the Association of American Geographers, 81 (1991):684-696.

Wikimapia. Site, disponível em <www.wikimapia®.org>, acessado em abril de 2014.

Zook, Matthew; Graham, Mark; Shelton, Taylor; Gorman, Sean. "Volunteered Geographic Information and Crowdsourcing Disaster Relief: A Case Study of the Haitian Earthquake". World Medical e Health Policy, 2 (2012).

Recebido em outubro de 2014. Aceito em março de 2015. 